ISSN = 1980-993X - doi:10.4136/1980-993X
www.agro.unitau.br/ambi-agua
E-mail: ambi-agua@agro.unitau.br
Tel.: (12) 3625-4116

\title{
Mapa de infiltração do alto e médio Vale do Paraíba do Sul com base em elementos do meio físico e na precipitação
}

(doi:10.4136/ambi-agua.40)

\author{
Paulo Valladares Soares ${ }^{1}$, Sueli Yoshinaga Pereira ${ }^{2}$, Silvio Jorge Coelho Simões ${ }^{3}$, \\ George de Paula Bernardes ${ }^{3}$, Sérgio Augusto Barbosa ${ }^{4}$ \\ ${ }^{1}$ Fundação Florestal, 02377-000, São Paulo \\ E-mail: pvsoares1@yahoo.com.br \\ 2 Instituto de Geociências, Unicamp, 13083-870, Campinas \\ E-mail: sueliyos@ige.unicamp.br \\ ${ }^{3}$ Laboratório de Análise Geoespacial, UNESP, Campus de Guaratinguetá, 12516-410, Guaratinguetá \\ E-mail: simoes@feg.unesp.br,gpb@feg.unesp.br \\ ${ }^{4}$ Agência Nacional de Águas - ANA, 70610-200, Brasília, DF \\ E-mail: sergio.barbosa@ana.gov.br
}

\section{RESUMO}

Este trabalho apresenta um procedimento para a elaboração de um Mapa de Infiltração, com base nas ferramentas disponíveis em um sistema de informação geográfica. A região utilizada para a avaliação dessa metodologia foi uma parte da bacia do rio Paraíba do Sul, que corresponde a uma área de $7.600 \mathrm{~km}^{2}$. Os elementos do meio físico utilizados foram a litologia, o relevo, o solo e o uso e a cobertura da terra. Também, foi considerada a distribuição espacial da precipitação. Para cada tipo de elemento do meio físico aplicou-se um fator de ponderação de 1 a 5, que por sua vez corresponde a maior (5) ou menor (1) influência desse elemento para a capacidade de infiltração. Os resultados apontam que as melhores áreas de infiltração situam-se na região da Bocaina, nos contrafortes da Serra do Mar, na região entre Cunha e Lagoinha, e em parte dos terrenos colinosos relacionados à Bacia Sedimentar de Taubaté. Em uma realidade de recursos hídricos escassos tanto para ações não estruturais (conservação do solo, reflorestamento) e ações estruturais (estações de tratamento de água e esgoto e programas de redução de perda de água) a elaboração de um mapa que estabeleça a condição espacial da infiltração se constitui numa importante ferramenta de gestão e planejamento territorial, de modo a preservar os recursos hídricos.

Palavras-chave: processos de infiltração; elementos da paisagem; sistemas de informação geográfica.

\section{Map of infiltration of the Paraíba do Sul basin using physical elements and precipitation}

\section{ABSTRACT}

This paper presents a methodological approach to characterize the infiltrations conditions of a portion of Paraiba do Sul river basin $\left(7,600 \mathrm{~km}^{2}\right)$ using Geographic Information Systems tools. To each landscape feature (rock, structure, relief, soil, and land-use) and to the spatial distribution of precipitation, an infiltration potential scale factor that ranges from higher influence (5) to lower influence (1) was applied considering its geographical position. The results showed that higher infiltration capacity areas are located in Serra da Bocaina associated to Serra do Mar relief in the Northeast region and Southeast region as well associated to gentle hills and sandstones along the Paraíba do Sul river. The creation of an Infiltration Map may contribute to the development of long-term territorial plans and water 
SOARES, P. V.; PEREIRA, S. Y.; SIMÕES, S. J. C.; BERNARDES, G. P.; BARBOSA, S. A. Mapa de infiltração do alto e médio Vale do Paraíba do Sul com base em elementos do meio físico e na precipitação. Ambi-Agua, Taubaté, v. 3, n. 1, p. 26-42, 2008. (doi:10.4136/ambi-agua.40)

resource management plans in order to support future implementation of non-structural and structural measures at both regional and local scales.

Keywords: infiltration process; landscape features; geographical information system.

\section{INTRODUÇÃO}

Os processos de infiltração, retenção e percolação são responsáveis pela manutenção da bacia hidrográfica como um reservatório dinâmico do sistema hidrológico, o qual permite a armazenagem e transferência de água como, por exemplo, pela movimentação da água subterrânea em direção aos cursos de água nos períodos de estiagem. Para se ter uma compreensão sistêmica dos processos de infiltração é necessário considerar as conexões existentes entre a água, os elementos do meio físico e a dinâmica do uso da terra.

Entretanto, a maior parte dos estudos que tratam com os processos de infiltração da água no solo são baseados apenas em ensaios pontuais o que requerem uma grande quantidade de ensaios analisados para que se obtenha a sua representação espacial. Como procedimento alternativo, nos últimos anos, começam a ser desenvolvidos estudos que buscam avaliar a distribuição espacial da infiltração com base em parâmetros do meio físico tais como geologia, geomorfologia e pedologia (Brito et al., 2006).

Nessa direção, o objetivo deste trabalho é apresentar uma metodologia que possibilite definir áreas potenciais de infiltração com base em elementos do meio físico natural e modificado (rochas, relevos, solos e uso e cobertura da terra) e sua interação com a variação espacial da precipitação. O trabalho procurou ainda avaliar a capacidade de integração e interação de um sistema de informação geográfico no sentido de se obter um mapa de potencialidade à infiltração. Este estudo foi realizado em escala regional utilizando, como estudo de caso, parte da bacia do Rio Paraíba do Sul, compreendendo tanto a sua área mais preservada como sua área fortemente modificada por ações antrópicas.

\section{ASPECTOS TEÓRICOS}

O ciclo hidrológico descreve a dinâmica da água na natureza consistindo em um conjunto de fases, nos quais são representados os diferentes caminhos que a água percorre nas diferentes escalas de abordagem. Participam do ciclo vários processos hidrológicos, como: precipitação, evaporação, transpiração, infiltração, armazenamento superficial, escoamento superficial e sub-superficial e percolação. O ciclo hidrológico pode ser entendido como uma série de armazenagens de água conectadas por transferências. O tempo de permanência, que é a duração média de tempo que a água permanece em uma parte da hidrosfera ou local de armazenamento, antes de mover-se para outra parte, indica que estas transferências podem ser mais lentas (água subterrânea, por exemplo) ou mais rápidas como nos rios que exercem limitada função de armazenagem.

A variação no armazenamento é função das inter-relações dos elementos naturais e modificados da paisagem que compõem o meio físico (rochas e estruturas, relevo, declividade, solo, uso e cobertura da terra) quanto às condições espaciais da precipitação. Nesse sistema físico, visto de forma integrada, pode-se atribuir à bacia o papel de regulação e alteração na distribuição temporal dos volumes de água.

Conforme destacam Dunne e Leopold (1978), o processo de infiltração é o resultado de relações interdependentes na entrada de água na superfície do solo, na armazenagem e na transmissão de umidade do interior do solo. Com base nos princípios estabelecidos por Horton no final da década de 30 e início da década de 40 e largamente difundidos nos livros 
especializados de hidrologia como por exemplo, Bras (1990), a capacidade de infiltração pode ser definida como a taxa máxima com que um determinado solo pode absorver água em uma determinada condição. A umidade, a permeabilidade, a temperatura do solo, a profundidade da camada impermeável, o grau de compactação do solo e o tipo de uso da terra, estão entre os principais fatores que influenciam na capacidade de infiltração de um determinado solo.

Condições de textura, profundidade e umidade antecedente do solo são variáveis que exercem influência na quantidade de água que poderá ser estocada antes do solo atingir a saturação. Solos profundos, bem drenados e com textura grosseira apresentarão alta capacidade de infiltração, enquanto os solos rasos e mais argilosos mostrarão baixas taxas e volumes de infiltração. Essas condições estão fortemente relacionadas com as características geológicas, geomorfológicas e pedológicas de uma determinada região.

As alterações antrópicas na superfície do solo mudam a absorção, a infiltração, a qualidade e a quantidade de água subterrânea; também têm o papel de acelerar os processos de fluxo de superfície. A Figura 1 mostra a magnitude da intervenção humana e a capacidade de alterar a eficiência das armazenagens e transferências no interior do solo. Se a interferência se der em modificações de superfície ou de solo, ou em armazenagens, é provável que uma reação seqüencial provoque mudanças em todo o restante dos depósitos e transferências. Por outro lado, a diminuição da capacidade do solo para absorver as chuvas, devido a prováveis mudanças no uso e cobertura da terra, poderá afetar a distribuição de água por todas as etapas anteriores. Portanto, não é de estranhar que a atividade antrópica (particularmente as mudanças no uso da terra) cause grande impacto nos processos de infiltração, conforme mostra a Figura 1.

Apesar de sua fundamental importância no contexto do ciclo hidrológico e na manutenção da "saúde hídrica" de uma bacia hidrográfica, a infiltração é considerada como uma "caixa preta" e tende muitas vezes a ser desprezada nos cálculos dos balanços hídricos e nos estudos hidrológicos regionais. O procedimento usual de se quantificar a infiltração nos solos é por meio de ensaios pontuais com base nos diferentes procedimentos descritos na literatura (e.g. Rewls et al., 1993). Estimativas pontuais da infiltração podem ser obtidas de maneira mais sofisticada, como aquela apresentada por Kwicklis et al. (2005), envolvendo uma combinação de técnicas que incluem o uso da equação de Richard, modelagem numérica e métodos de balanço de massa utilizando cloro. Kwicklis et al. (2005) utilizam esse conjunto de técnicas para quantificar a infiltração e obter um mapa de infiltração em uma área em torno de $600 \mathrm{~km}^{2}$ na região de Los Alamos, Novo México, EUA.

Entretanto, no caso do Brasil, querer obter a espacialização da infiltração a partir de técnicas pontuais é muito difícil, em face do elevado custo dos ensaios, mesmo para áreas de pequenas dimensões (poucos $\mathrm{km}^{2}$ ), necessitando uma significativa quantidade de dados para gerar um mapa de boa qualidade a partir de técnicas de interpolação.

No caso de áreas de grandes dimensões (a partir de centenas de $\mathrm{km}^{2}$ ), a produção de um mapa de infiltração, a partir de ensaios quantitativos pontuais, torna-se inviável. Logo, devese buscar alternativas, com base em elementos do meio físico, que possam refletir, espacialmente, os processos de infiltração, tornando-os procedimentos qualitativos ou semiquantitativos. Uma proposta seria estabelecer mapas de infiltração com base na "classificação hidrológica de solos" (Ward e Eliot, 1995; Thompson, 1999), em que se define uma capacidade mínima de infiltração (em $\mathrm{mmh}^{-1}$ ) em função da sua textura. Um exemplo de mapa construído com base na classificação hidrológica dos solos foi aquele construído por Civita e Maio (1997), utilizando as ferramentas de um sistema de informação geográfico. 


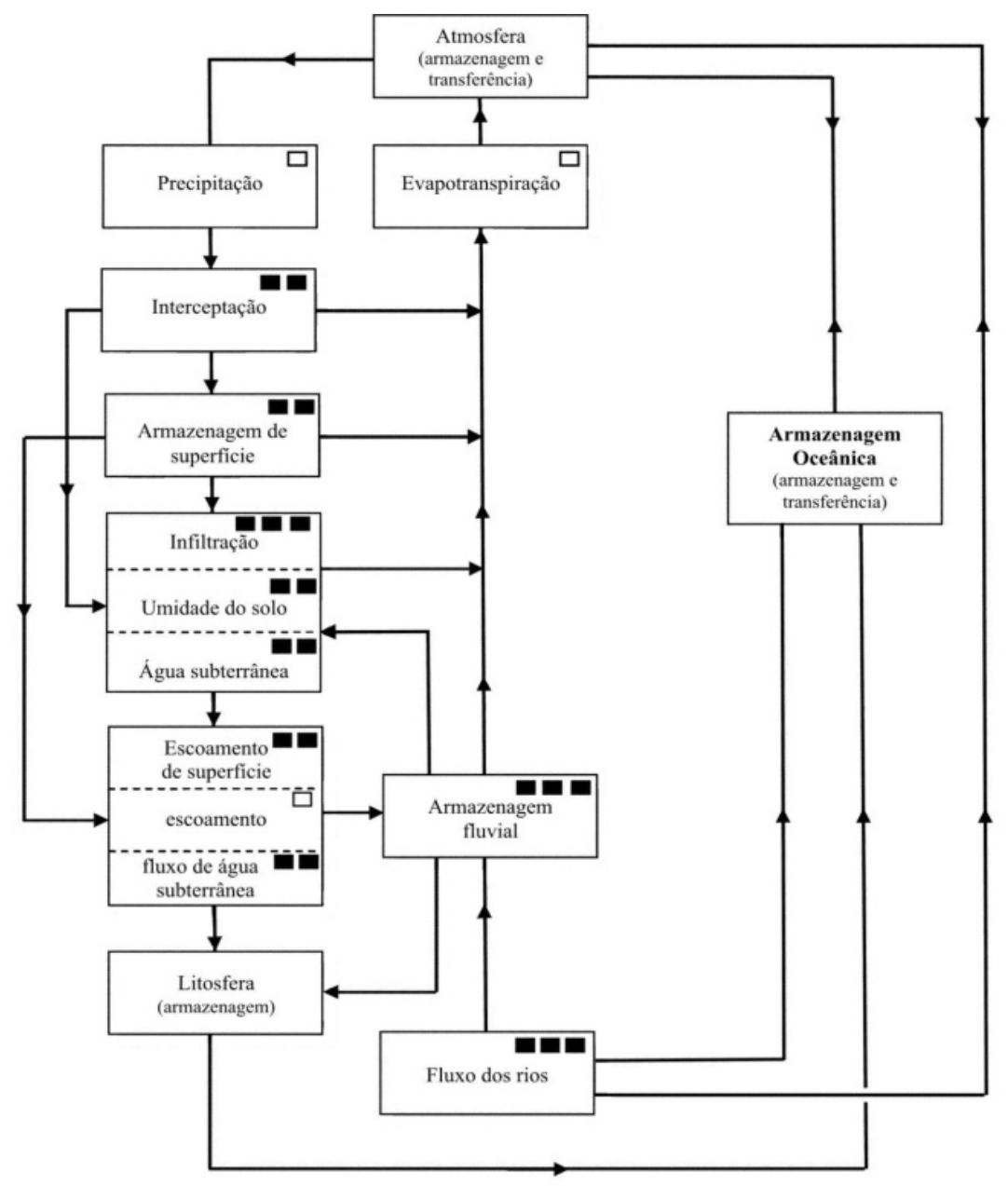

PONTOS DE INTERVENÇÃO HUMANA

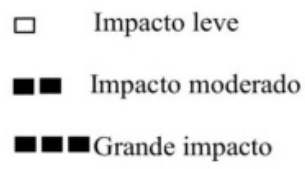

Figura 1. Representação do ciclo hidrológico mostrando os pontos de intervenção humana modificado de Drew (1994).

Embora os tipos de solos possam, de certa forma, refletir a capacidade de infiltração é importante lembrar que os processos de infiltração são controlados por diversos outros fatores como a precipitação, as características morfométricas do relevo, os tipos de rochas e suas estruturas, os tipos de vegetação, o uso e cobertura da terra, entre outros. Isso exige a construção de mapas de integração, como é o caso do "mapa de potencial de infiltração e recarga”, proposto por Gonçalves et al. (2007), que levaram em consideração diversos fatores do meio físico, uso da terra e características dos sistemas porosos e fraturados.

Outro caminho seria associar áreas de maior ou menor infiltração a partir do que foi designado por Brito et al. (2006) como "parâmetros hidrogeológicos". Esses autores consideraram quatro parâmetros (geologia, solo, declividade e áreas de inundação) e definiram diferentes pesos para cada um deles.

Finalmente, é preciso considerar que a relação entre a capacidade de infiltração e a capacidade de recarga dos aqüíferos nem sempre é direta e, como sugerem Kwicklis et al. (2005), diversos fatores podem complicar esta relação. Por exemplo, essa dificuldade pode 
ocorrer em regiões de aluviões, onde a direção de movimento da água de superfície e da água subterrânea nem sempre é clara ou em regiões compostas por rochas ígneas e metamórficas, onde a localização de fraturas armazenadoras de água pode ser uma tarefa bastante complexa necessitando de informações geoestruturais, hidrogeológicas e geofísicas.

\section{MATERIAIS E MÉTODOS}

Ao se analisar os mapas temáticos da área estudada, pode-se constatar a grande diversidade dos elementos do meio físico e das distintas formas de uso e ocupação da terra, evidenciando bem a complexidade mencionada acima. Uma maneira de resolver essa questão foi buscar estabelecer um grupo de especialistas com diferentes formações com o objetivo de avaliar cada elemento do meio físico selecionado. Inicialmente, buscou-se avaliar a importância relativa de cada elemento para a infiltração. Por exemplo, a geomorfologia teria mais importância que a pedologia, ou vice-versa? Em face da dificuldade em responder essa questão, assumiu-se que todos os elementos teriam o mesmo peso, ainda que isso pudesse mascarar uma maior importância relativa de um determinado elemento sobre outro. O grupo de especialista definiu para análise elementos do meio físico natural (rocha, solo, relevo e precipitação) e modificado (uso e cobertura da terra). Essa escolha se deve, principalmente, por dois fatores: a) a significativa importância desses elementos para o processo de infiltração; b) a base cartográfica disponível.

Para a produção do mapa final de infiltração levou-se em conta a base cartográfica existente no levantamento realizado durante a execução do Plano de Qualidade de Água para a porção paulista da bacia do Paraíba do Sul (CEIVAP, 2000). Infelizmente, existe uma discrepância de escala entre os levantamentos básicos efetuados. Para a região de estudo, a situação mais crítica são os levantamentos pedológicos e geomorfológicos. Em face disso, a escala de representação do mapa final de integração corresponde a mesma desses dois mapas (1:500.000).

Para as diferentes unidades (geológicas, geomorfológicas, pedológicas e de uso e cobertura do solo) e faixas (precipitação) atribuíram-se pesos que variam de um (1) a cinco (5) em que são analisados os comportamentos individuais de cada elemento aos processos de infiltração. Os pesos simbolizam a importância de cada tema (classes) para o sistema de análise conforme a sugestão da equipe de especialistas e a partir de informações bibliográficas. Esses números identificam o tipo de classe de um determinado mapa temático que ocorre em uma determinada unidade de terreno no interior da área de estudo. Quanto mais importante for uma classe em relação a determinado requisito, maior será seu peso para o referido requisito, indicando, portanto, condições mais favoráveis à infiltração (Tabela 1).

Tabela 1. Relação de qualificadores e seus respectivos pesos relativos.

\begin{tabular}{lc}
\hline \multicolumn{1}{c}{ Qualificadores } & Pesos Relativos \\
\hline Muito Baixa & 1 \\
Baixa & 2 \\
Regular & 3 \\
Boa & 4 \\
Muito Boa & 5 \\
\hline
\end{tabular}

Para executar a interação dos elementos do meio físico com seus respectivos pesos utilizaram-se as ferramentas de integração de dados do software ArcGIS ${ }^{\circledR}$. O procedimento 
para a geração do mapa de infiltração constou da aplicação de pesos segundo a característica específica de cada tema. O mapa final contém todos os cruzamentos espaciais realizados. No arquivo digital desse mapa foi calculada a média dos valores obtidos em todos os polígonos gerados, somando-se, para cada polígono, os pesos de infiltração dos temas e dividindo pelo número total de temas cruzados. Em seguida, foram definidos os intervalos entre os valores mínimos e os valores máximos encontrados na área de estudo. Dessa forma foi possível definir áreas homólogas em função da capacidade de infiltração tornando possível a espacialização e visualização de um mapa temático final.

\section{DESCRIÇÃO DA ÁREA DE ESTUDO}

A bacia do rio Paraíba do Sul está inserida nos territórios dos estados de São Paulo $\left(13.900 \mathrm{~km}^{2}\right)$, Rio de Janeiro $\left(20.900 \mathrm{~km}^{2}\right)$ e Minas Gerais $\left(20.700 \mathrm{~km}^{2}\right)$ onde vivem cerca de 14,3 milhões de pessoas em uma das mais importantes regiões industriais do país e onde se localizam várias cidades de médio e grande porte. A área de estudo (Figura 2), com aproximadamente $6.400 \mathrm{~km}^{2}$ de área total, compreende os municípios Cunha, Lagoinha, Roseira, Aparecida, Guaratinguetá, Potim, Canas, Lorena, Piquete, Cachoeira Paulista, Queluz, Lavrinhas, Cruzeiro, Silveiras, Areias, São José do Barreiro, Arapeí e Bananal.

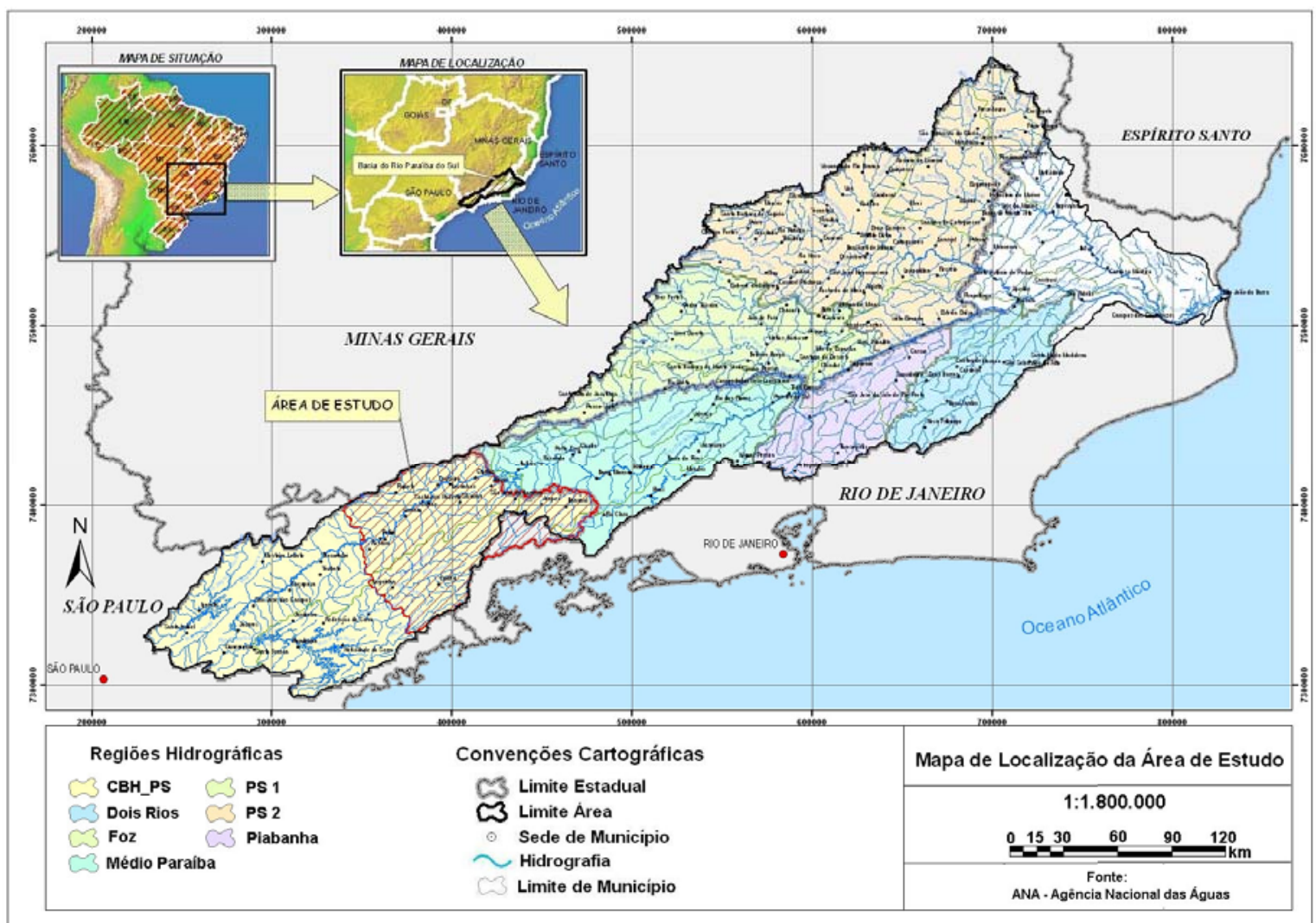

Figura 2. Regiões hidrográficas da bacia do rio Paraíba do Sul e localização da área de estudo.

A porção paulista da bacia, onde se localiza a área de estudo, pode ser dividida em quatro compartimentos com base nas características históricas, sociais, econômicas e ambientais: nascente, reservatório, urbano-industrial e agrícola-urbano-industrial (Figura 3). O compartimento nascente corresponde ao trecho onde estão inseridas as bacias hidrográficas 
que compõem os formadores do rio Paraíba do Sul (rio Paraibuna e rio Paraitinga). O compartimento reservatório é a região onde deságuam os formadores do rio Paraíba do Sul, constituindo o sistema de represa gerenciado pela CESP. O compartimento urbano-industrial constitui o eixo de maior desenvolvimento tecnológico e industrial da região, com processos acelerados e desordenados de urbanização, conurbação e altos índices de poluição hídrica. O compartimento agrícola-urbano-industrial corresponde ao último trecho da bacia hidrográfica do rio Paraíba do Sul no Estado de São Paulo e caracteriza-se, também, por pastagens degradadas, intensa fragmentação florestal, início de processos de conurbação e crescente atividade industrial. A área de estudo corresponde mais especificamente ao compartimento nascente e ao compartimento agrícola-urbano-industrial.

A região de estudo possui alta diversidade do meio físico, o qual é o resultado de uma evolução geológica complexa (IPT, 1981; Ross e Moroz, 1997). Na região é possível identificar três unidades geológicas-geomorfológicas bem distintas: a) rochas precambrianas associadas com relevos de morros e serras; b) sedimentos terciários associados a relevos suaves; e c), sedimentos quaternários associados a extensas planícies aluvionares. Esta grande diversidade geológica-geomorfológica tem contribuído para o desenvolvimento de diversas unidades pedológicas, tais como latossolos, argissolos, cambissolos e gleissolos melânicos (Oliveira et al., 1999). A grande variação altimétrica observada na área de estudo (entre 450 m e $2000 \mathrm{~m}$ ) favorece os processos orográficos sendo, em parte, responsável pela significativa variabilidade temporal (entre 1.300 e $2.400 \mathrm{~mm} / \mathrm{ano}$ ) e espacial das precipitações regionais (Silva, 1999; Simões e Barros, 2007).

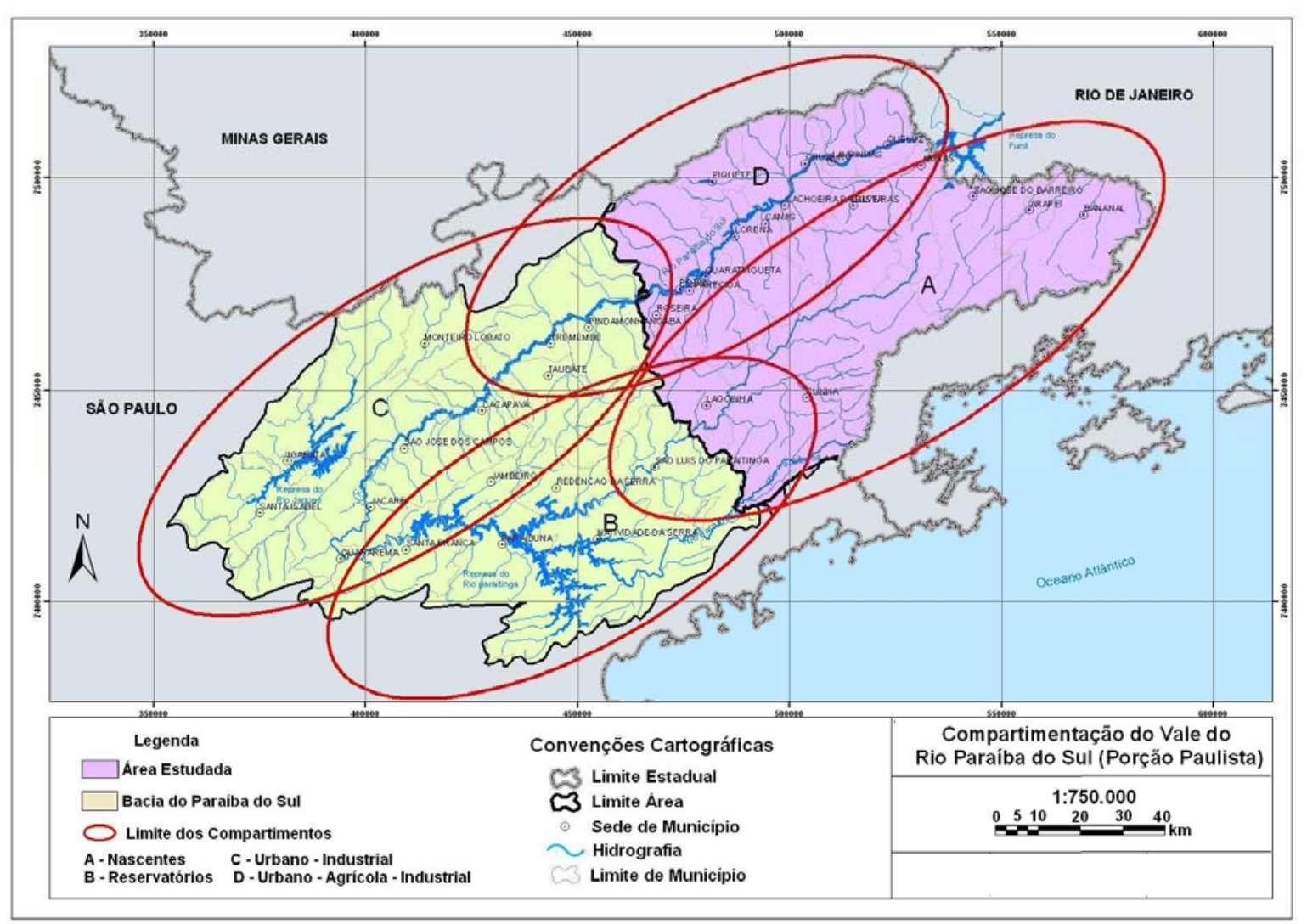

Figura 3. Compartimentação da bacia do Paraíba do Sul (porção paulista). A - nascente, B reservatório, C - urbano-industrial, D - urbano-agrícola-industrial. 
Em termos de distribuição espacial, as áreas de pastos/campos representam cerca de $50 \%$ da área total da bacia e pode-se constatar uma paisagem com elevado grau de fragmentação, na qual se destacam as áreas de mata nativa $(17,4 \%)$, capoeira $(13,4 \%)$, reflorestamento (9,0\%), pastagem de várzea (3,3\%), agricultura de várzea (1,0\%) áreas urbanizadas (2,9\%) e reservatórios (1,4\%), conforme levantamento realizado pelo CEIVAP (2000). Considerando a terminologia utilizada pela Ecologia da Paisagem, essas áreas se constituem no elemento matriz, enquanto os demais usos seriam pedaços (patches) inseridos na matriz (Forman e Godron, 1985; Forman, 1995).

\section{RESULTADOS}

\subsection{Geologia}

O mapa geológico utilizado foi produzido pelo IPT (1981), em escala 1:500.000, o qual é mostrado na Figura 4, para a área de estudo. Nesse mapa é possível identificar 9 unidades geológicas distintas. Na área de estudo, destacam-se duas grandes unidades: o embasamento cristalino, de idade precambriana, representado por granitos, migmatitos homogêneos e heterogêneos, quartzitos e filitos e a bacia sedimentar do Taubaté, composta por depósitos continentais flúvio-lagunares de idade terciária e sedimentos aluvionares de idade quaternária.

As rochas ígneas e metamórficas, como granitos e gnaisses, por serem impermeáveis, têm sua condição de infiltração dependendo completamente do comportamento do fraturamento. As melhores condições seriam fraturas abertas, em várias direções e com elevada densidade. No caso das rochas sedimentares, a porosidade e a permeabilidade são controladas pela composição das rochas favorecendo aquelas de composição arenosa.

As rochas com melhores condições de infiltração são os arenitos (peso 5) com lentes subordinadas de folhelhos. Em seguida, encontra-se o substrato granítico (peso 4) rico em minerais félsicos (claros) - como quartzo e feldspato - que propiciam mantos de alteração composto de sedimentos relativamente grosseiros e grau elevado de fraturamento e os migmatitos homogêneos (peso 3), com manto de alteração mais fino de composição arenoargilosa. Os aluviões, em geral, constituem-se nas condições menos favoráveis à infiltração (peso 1) com composição bastante variada (IPT, 1981).

\subsection{Pedologia}

O Mapa Pedológico do Estado de São Paulo (Oliveira et al., 1999), desenvolvido a partir do Sistema de Classificação de Solos da EMBRAPA, constitui-se no mais recente levantamento pedológico regional disponível para o estado e foi utilizado como base para a área de estudo. Regionalmente, seis unidades pedológicas bem distintas foram identificadas (Figura 5).

Para se avaliar as condições de infiltração desses solos, levou-se em consideração, além da classificação proposta por Oliveira et al., (1999), a classificação hidrológica dos solos com base na sua capacidade de infiltração (Ward e Elliot, 1995). Nessa classificação são definidas quatro classes avaliadas em condições de saturação dos solos, a saber: a) solos com alta capacidade de infiltração, consistindo de solos profundos e com drenagem boa à excessiva (na área de estudo correspondem aos latossolos); b) solos com capacidade de infiltração moderada com profundidades relativamente rasas e textura variável (na área de estudo, correspondem aos cambissolos); c) solos com baixa capacidade de infiltração, consistindo de camadas impermeáveis que dificultam o movimento descendente da água (na região de estudo correspondem aos argissolos); d) solos com capacidade de infiltração muito baixa consistindo de solos argilosos com elevado potencial de agregação, ou com nível freático próximo à 
SOARES, P. V.; PEREIRA, S. Y.; SIMÕES, S. J. C.; BERNARDES, G. P.; BARBOSA, S. A. Mapa de infiltração do alto e médio Vale do Paraíba do Sul com base em elementos do meio físico e na precipitação. Ambi-Agua, Taubaté, v. 3, n. 1, p. 26-42, 2008. (doi:10.4136/ambi-agua.40)

superfície (na área de estudo corresponderiam aos cambissolos húmicos e aos gleissolos melânicos).

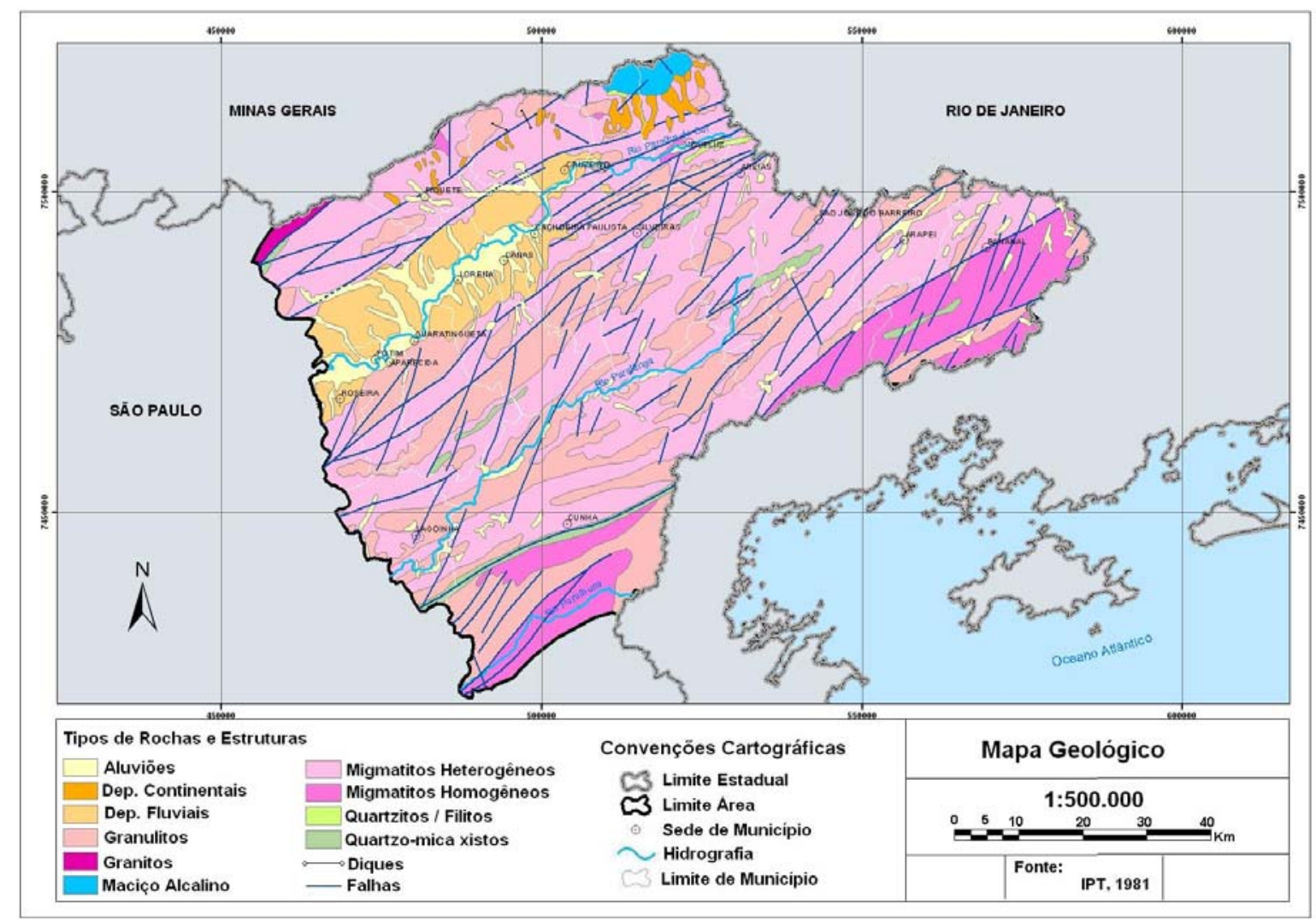

Figura 4. Mapa Geológico da área de estudo (IPT, 1981) mostrando as diferentes unidades litológicas e as principais direções de lineamento regionais.

Os latossolos vermelho-amarelos são os que apresentam as melhores condições de infiltração (peso 5) em face de ser bem desenvolvidos, não apresentarem minerais primários e terem boa condição de drenagem. Os cambissolos háplicos e húmicos, ainda que tenham horizonte B pouco espesso receberam pesos de infiltração 4 e 3, respectivamente. Um aspecto que facilita o processo de infiltração nos cambissolos é a presença de minerais primários facilmente alteráveis. Os argissolos vermelho-amarelo com horizonte B textural, enriquecidos em argila foram considerados como tendo baixa condição de infiltração (peso 2). Os gleissolos melânicos, ricos em argila e matéria orgânica e com nível freático próximo à superfície representam as condições menos favoráveis à infiltração (peso 1) representando condições de descarga de aqüífero. 
SOARES, P. V.; PEREIRA, S. Y.; SIMÕES, S. J. C.; BERNARDES, G. P.; BARBOSA, S. A. Mapa de infiltração do alto e médio Vale do Paraíba do Sul com base em elementos do meio físico e na precipitação. Ambi-Agua, Taubaté, v. 3, n. 1, p. 26-42, 2008. (doi:10.4136/ambi-agua.40)

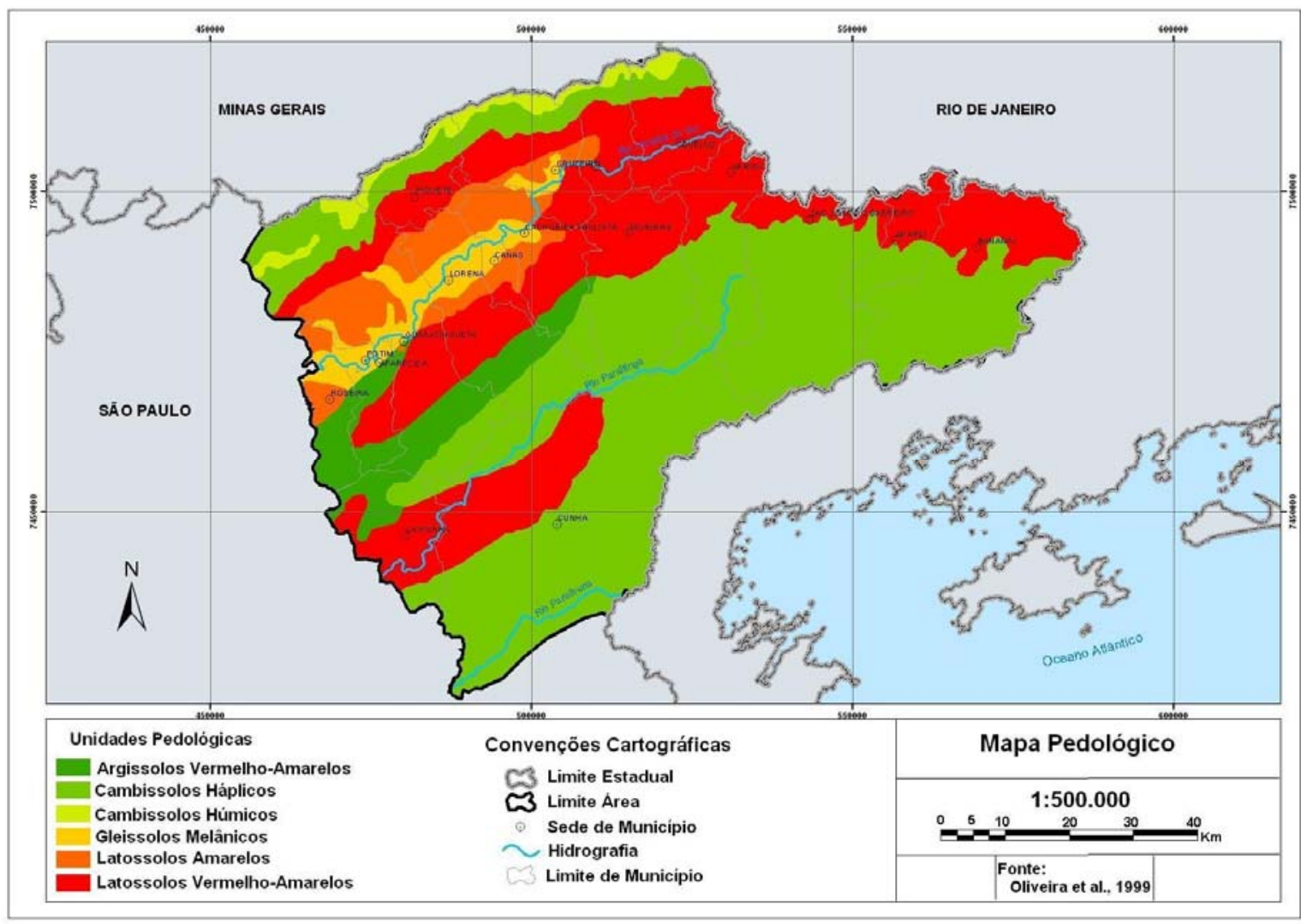

Figura 5. Mapa Pedológico da área de estudo no qual foram identificados seis unidades distintas. Fonte: Oliveira et al. (1999).

\subsection{Geomorfologia}

A região de estudo está inserida na Província Geomorfológica do Planalto Atlântico, caracterizando-se pelas zonas do Planalto Paraitinga, Planalto Bocaina, Médio Vale do Paraíba e parte da Serra da Mantiqueira conforme Ross e Moroz (1997). A análise dos elementos do relevo foi realizada tomando-se como base o Mapa Geomorfológico do Estado de São Paulo nas escalas 1:1.000.000 (Ponçano et al., 1981) e 1:500.000 (Ross e Moroz, 1997) (Figura 6).

Em face da escala de representação, preferiu-se utilizar o mapa geomorfológico o qual representa as diferentes unidades de relevo, contendo informações sobre a morfologia, a morfometria, a litologia entre outros. Dessa maneira, consegue-se expressar melhor a diversidade e as feições do relevo na região do que utilizando apenas a declividade.

Para a região de estudo foram identificadas doze unidades geomorfológicas, variando de planícies aluvionares (com baixíssima declividade) até relevos de serras (com declividades superiores a $100 \%)$.

Os relevos de colinas amplas, topos e extensos e aplainados, drenagem de baixa intensidade e vales abertos representam as melhores condições de infiltração (peso 5). Os relevos de morrotes baixos e morros paralelos foram considerados como tendo boas condições de infiltração (peso 4), particularmente por apresentarem topos arredondados e vales que variam de fechados a abertos. Em uma situação intermediária, encontram-se os relevos constituídos de morrotes e espigões com drenagem de média a alta densidade e vales fechados (peso 3). Os relevos de escarpas com topos angulosos, drenagem de alta densidade e vales fechados possuem condições pouco favoráveis à infiltração (peso 2). Os terrenos baixos e 
SOARES, P. V.; PEREIRA, S. Y.; SIMÕES, S. J. C.; BERNARDES, G. P.; BARBOSA, S. A. Mapa de infiltração do alto e médio Vale do Paraíba do Sul com base em elementos do meio físico e na precipitação. Ambi-Agua, Taubaté, v. 3, n. 1, p. 26-42, 2008. (doi:10.4136/ambi-agua.40)

planos nas margens dos rios e sujeitos a inundação representam as condições menos favoráveis a infiltração (peso 1).

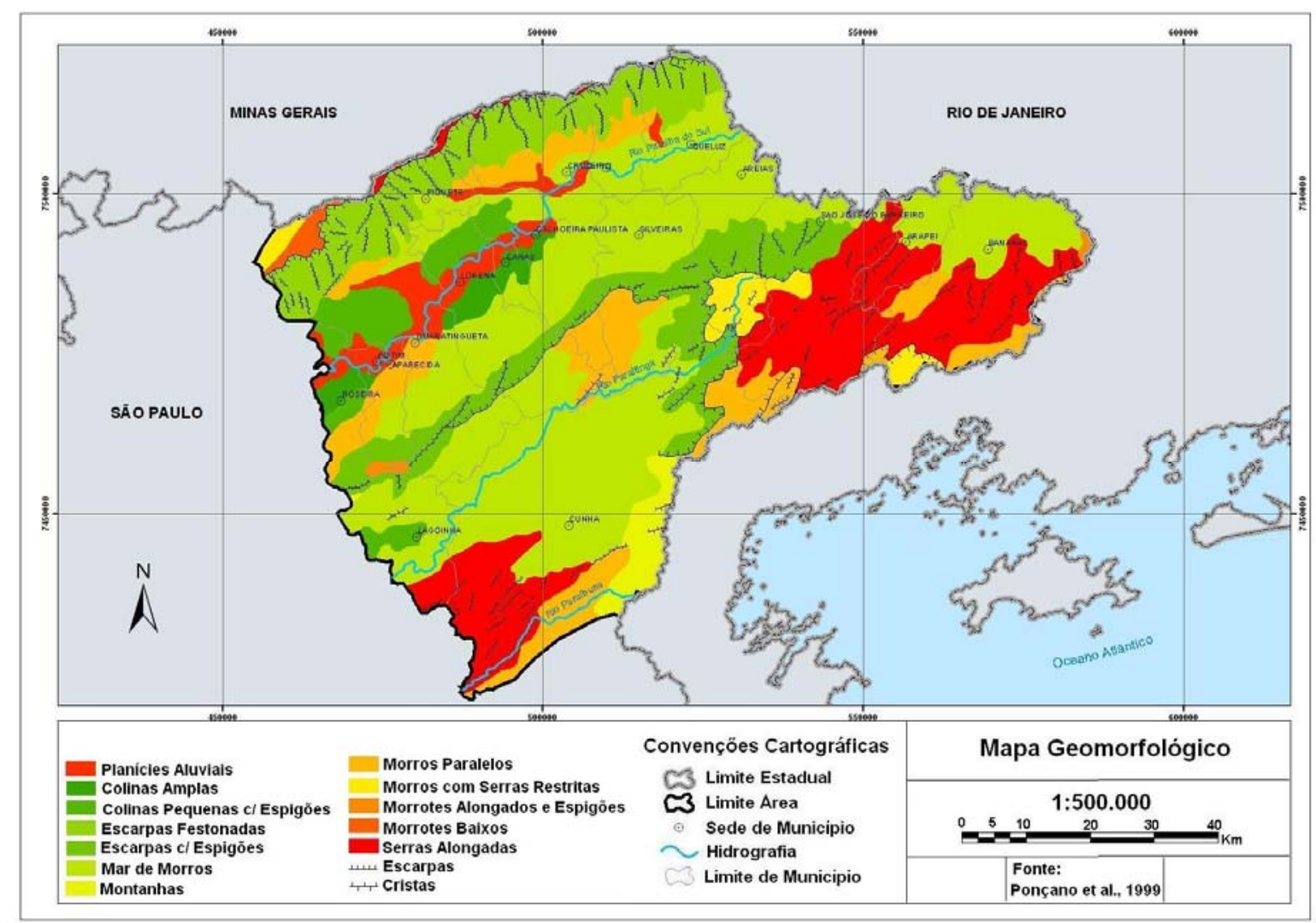

Figura 6. Mapa Geomorfológico mostrando a grande diversidade de tipos de relevos encontrados na área de estudo.

Fonte: Ponçano et al. (1981).

\subsection{Precipitação}

A região sudeste do Brasil apresenta grande diversidade no seu regime de chuvas, em face de ser uma zona de transição entre o regime tropical e o de média latitude (Rao e Hada, 1990). Além dessa diversidade, o padrão de precipitação da região do Vale do Paraíba é fortemente influenciado pelo efeito orográfico das chuvas devido à presença das serras do Mar e da Mantiqueira, que acrescentam maior complexidade aos processos climatológicos da região.

Uma das melhores maneiras de representar a variabilidade espacial da precipitação em uma região constituída de relevos íngremes é pelo método das isoietas, que é indicado para regiões com elevada diversidade topográfica (Thompson, 1999). Com base na configuração das isoietas da região de estudo, pode-se observar, a partir da Figura 7, que as precipitações mais elevadas - assim como as maiores diferenças nas precipitações - estão associadas às Serras da Mantiqueira (1300 a $2200 \mathrm{~mm}$ ) e a Serra do Mar (1300 a $2800 \mathrm{~mm}$ ). Em contraste, a região plana conhecida como Vale do Paraíba possui os menores índices de precipitação anual da bacia oscilando entre 1200 e 1300 mm. Portanto, a Figura 7 mostra claramente a importância do efeito orográfico sobre a distribuição espacial das precipitações.

No que concerne à infiltração, a utilização da pluviosidade média anual como entrada de água no sistema de bacias hidrográficas, está associada à idéia de que as maiores alturas de precipitação possuem maior probabilidade de contribuir para o processo de infiltração. Dessa 
maneira foram estabelecidas oito faixas de pluviosidade para a região considerada. Entre os maiores valores de precipitação média anual (peso 5) e os menores (peso 1) estabeleceram-se faixas intermediárias, as quais foram definidas de forma arbitrária.

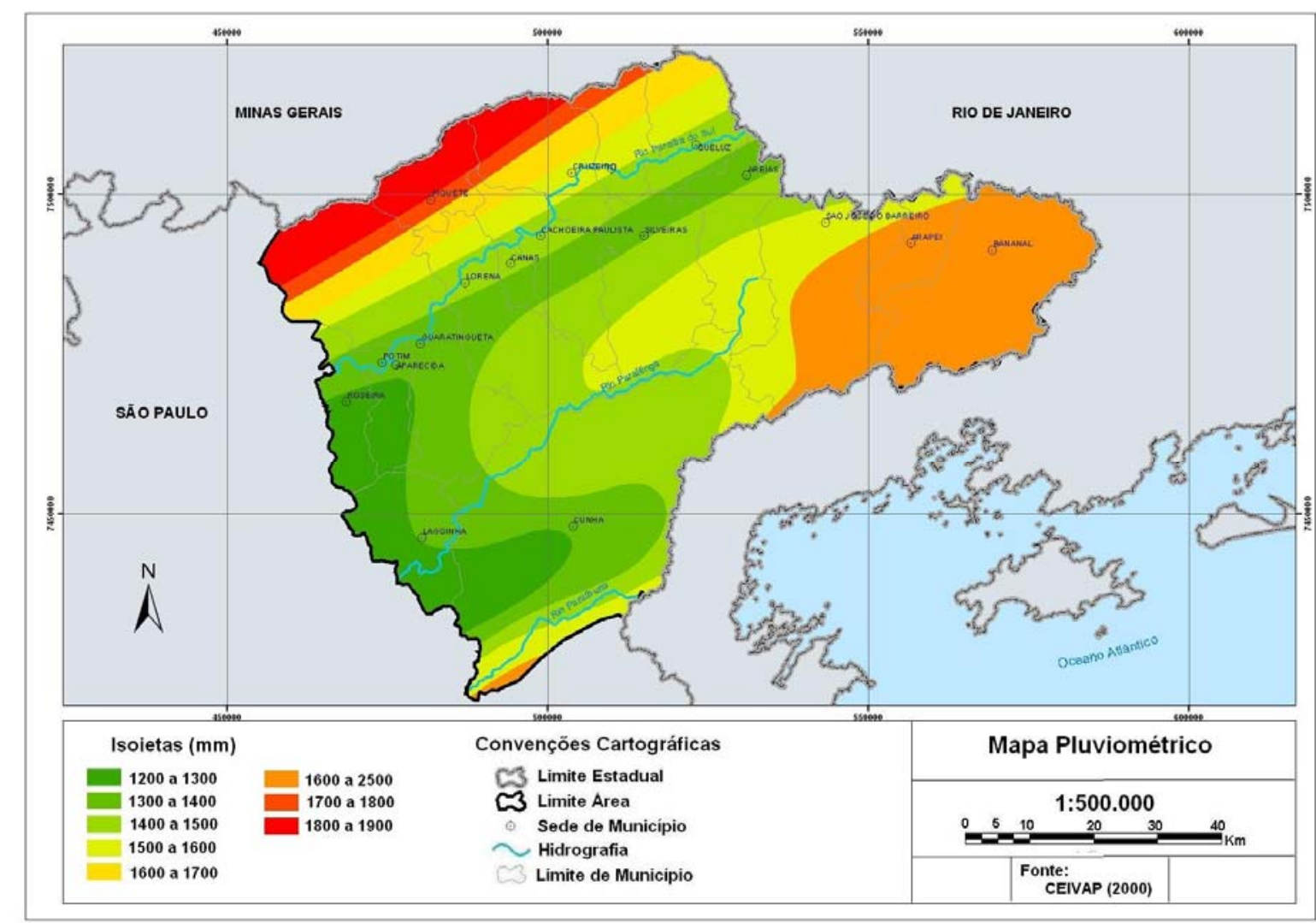

Figura 7. Mapa de Pluviometria, área de estudo construído a partir do método de isoietas.

Fonte: CEIVAP (2000).

\subsection{Uso e Cobertura da Terra}

Entre todos os critérios, o uso e cobertura da terra é aquele onde é possível se estabelecer a melhor correlação com os processos de infiltração, em face da grande quantidade de trabalhos existentes na literatura, inclusive com dados quantitativos.

Por outro lado, a definição das classes de uso da terra é um processo que envolve certa subjetividade e está fortemente correlacionado à escala de trabalho proposta. Neste estudo utilizou-se a metodologia adotada pelo Instituto Florestal no qual o Mapa de Uso e Cobertura Vegetal Natural foi elaborado por meio da interpretação de imagens do satélite LANDSAT 7 (Figura 8) e produzido dentro do Plano de Qualidade de Água da Bacia do Rio Paraíba do Sul, porção paulista (CEIVAP, 2000).

Assim, utilizou-se como base as classes de uso e cobertura propostas por Pereira et al. (1988) sendo elas: urbanização, pastagem, capoeira, reflorestamento e mata. Como era de se esperar, a formação vegetal constituída de matas com estrutura complexa e elevada biodiversidade possui as melhores condições de infiltração (peso 5), seguidas pelas áreas homogêneas de plantio de reflorestamento (peso 4). As florestas secundárias em estágio inicial de recuperação apresentando porte arbustivo até arbóreo representam situação intermediária (peso 3). As áreas de pastagem mal manejadas ligadas às atividades agropastoris extensivas receberam peso 2. As áreas com condições menos favoráveis de infiltração (peso 1) estão associadas aos núcleos urbanos e zonas de expansão urbana, caracterizadas pela presença de muitos lotes e impermeabilização da estrutura urbana. 
SOARES, P. V.; PEREIRA, S. Y.; SIMÕES, S. J. C.; BERNARDES, G. P.; BARBOSA, S. A. Mapa de infiltração do alto e médio Vale do Paraíba do Sul com base em elementos do meio físico e na precipitação. Ambi-Agua, Taubaté, v. 3, n. 1, p. 26-42, 2008. (doi:10.4136/ambi-agua.40)

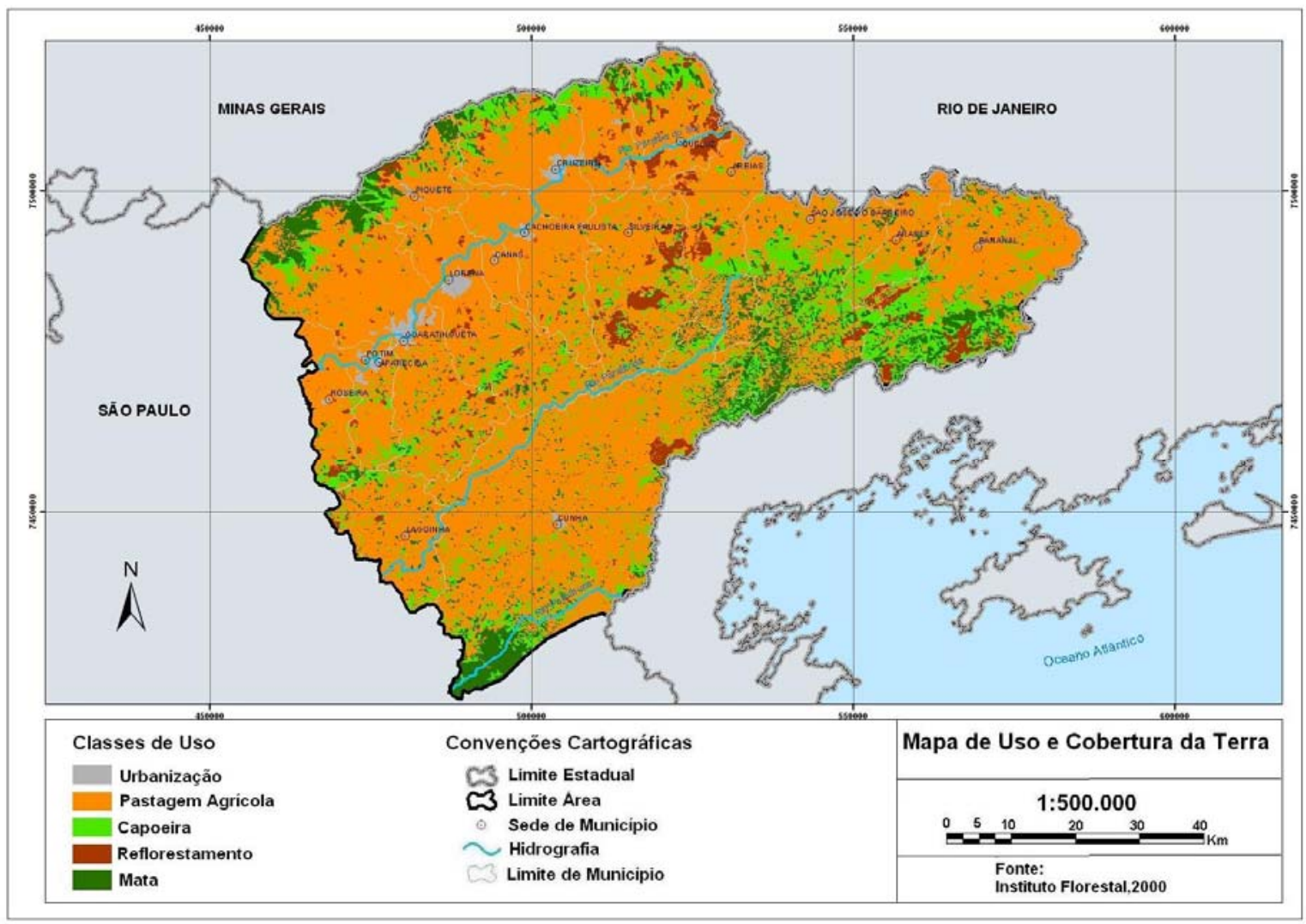

Figura 8. Mapa de Uso e Cobertura da Terra identificando as cinco principais classes encontradas na região.

Fonte: CEIVAP (2000).

\subsection{Mapa de Potencialidade a Infiltração}

Embora as classes dentro dos planos de informação possam responder de forma individual, suas características quanto à capacidade de infiltração estão ligadas à integração dos elementos do meio físico e constituem-se numa interessante forma de análise na distribuição espacial das condições de infiltração.

Pelo procedimento metodológico descrito no item 3, a identificação de regiões com boa capacidade de infiltração representam aquela que tem a melhor conjugação de possibilidades para que a água permaneça e se infiltre no perfil de solo. O mapa da Figura 9 representa as regiões com maior ou menor facilidade de infiltração com base nos elementos analisados.

A partir da Figura 9, observa-se que o extremo nordeste da área, correspondendo à Serra da Bocaina, apresenta a maior área contínua com boa capacidade de infiltração. Isso pode ser explicado por um conjunto de fatores positivos como elevadas precipitações médias anuais (1800 a $1900 \mathrm{~mm})$, relevos predominantes de morros e morrotes, declividades médias baixas (3 a 12\%), predominância de solos homogêneos e com boa drenagem (latossolos vermelhoamarelos) e alto grau de fraturamento. Áreas expressivas com boas condições de infiltração ainda ocorrem nos contrafortes da Serra do Mar, na região entre Cunha e Lagoinha e em parte dos terrenos colinosos que acompanham o rio Paraíba do Sul, na porção norte da área. Nos contrafortes da Serra do Mar, as áreas de boa condição de infiltração englobam as nascentes dos rios Paraibuna e Paraitinga. 
SOARES, P. V.; PEREIRA, S. Y.; SIMÕES, S. J. C.; BERNARDES, G. P.; BARBOSA, S. A. Mapa de infiltração do alto e médio Vale do Paraíba do Sul com base em elementos do meio físico e na precipitação. Ambi-Agua, Taubaté, v. 3, n. 1, p. 26-42, 2008. (doi:10.4136/ambi-agua.40)

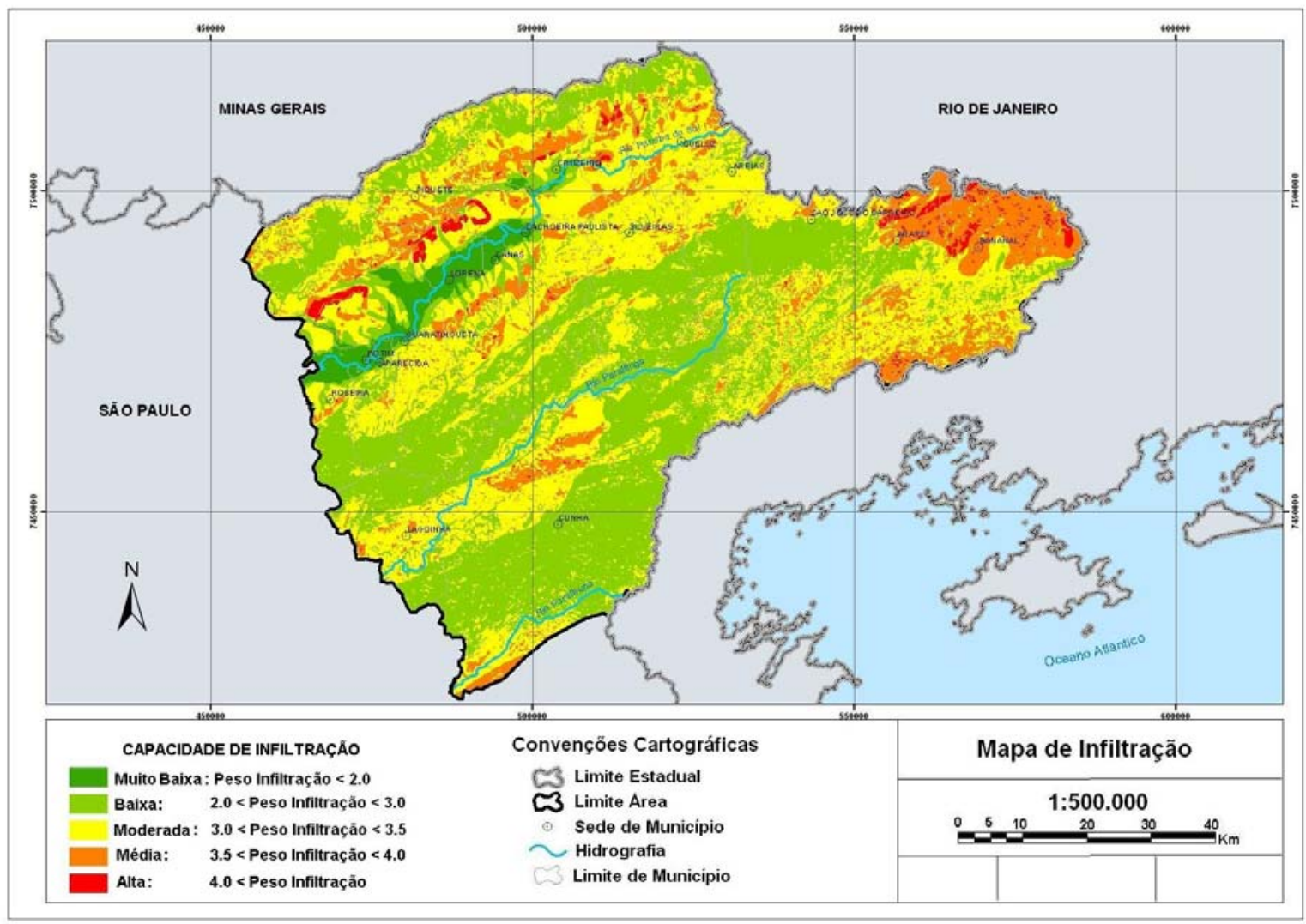

Figura 9. Mapa de Potencialidade de Infiltração, em que as porções identificadas em vermelho representam as áreas com maior potencial para a infiltração.

As áreas com boa capacidade de infiltração ocorrem de forma fragmentada e são caracterizadas por fatores como pluviometria média (1400 a $1600 \mathrm{~mm})$ e relevos predominantemente constituídos de serras e solos de B textural incipiente (cambissolos). De uma maneira geral, essas condições não seriam muito favoráveis à infiltração. Entretanto, as condições de uso e cobertura da terra são muito favoráveis, pois nessa região se concentra a maior parte dos fragmentos de mata da área de estudo. Na região entre Cunha e Lagoinha (centro-sul da área), existe uma "mancha" que apresenta uma boa capacidade de infiltração. Nessa região, as precipitações são relativamente baixas (1400 a 1500 mm). Entretanto, diversos condicionantes do meio físico são favoráveis à infiltração, tais como: o predomínio de morros e morrotes, as baixas declividades (3-12\%), a presença de granitóides muito fraturados e a presença de latossolos vermelho-amarelos. Na porção norte da área, ocorre uma estreita faixa de terrenos com boa infiltração. Essa área está inserida em elementos da paisagem com condições favoráveis de infiltração tais como: relevos colinosos, baixas declividades (3-12\%) e latossolos vermelho-amarelos.

As condições menos favoráveis de infiltração ocorrem em diversas áreas no interior da região estudada, tais como: no extremo sul (região entre Cunha e São Luis do Paraitinga), no extremo norte (Serra da Mantiqueira), em uma longa faixa SW-NE, dividindo a área ao meio (Serra do Quebra Cangalha) e na porção noroeste (planície aluvionar do rio Paraíba do Sul). Na região da Serra do Quebra Cangalha, a precipitação média anual é relativamente baixa (1200 a $1400 \mathrm{~mm})$. O relevo é formado predominantemente por uma escarpa estabelecendo um divisor de águas entre a região compreendida entre a Serra do Mar e a Serra do Quebra Cangalha e entre a Serra da Mantiqueira e a Serra do Quebra Cangalha. As declividades são relativamente elevadas (30 a 100\%) e os relevos estão em uma zona de transição entre os 
latossolos e os cambissolos. Na planície aluvionar do Rio Paraíba do Sul, as condições de infiltração são muito reduzidas devido às condições de baixa permeabilidade dos solos predominantes (gleissolos melânicos), os quais são ricos em argila e matéria orgânica. Esses solos estão, na sua maioria, em condições próximas à saturação (solos hidromórficos) e, considerando o modelo de circulação de água adotado neste trabalho, essas áreas se constituem descarga de aqüífero.

De uma maneira geral, a região entre a Serra do Quebra Cangalha e a Serra do Mar apresenta condições de infiltração variando de boa a moderada. O mapa da Figura 9 mostra claramente a importância dessa faixa — ou compartimento — como área de produção e disponibilização de água para o sistema Paraíba do Sul.

\section{CONCLUSÃO}

Este trabalho faz uso de elementos do meio físico, natural e modificado (rochas, estruturas, relevo, solos e uso e cobertura da terra) e precipitação para definir áreas com maior potencial de infiltração, considerando dois importantes compartimentos da bacia do rio Paraíba do Sul (porção paulista). No compartimento nascente (A), as áreas com melhores condições de infiltração ocorrem de forma fragmentada, estando associadas, principalmente, aos fragmentos de matas e às elevadas precipitações médias, ainda que os solos sejam relativamente incipientes. No compartimento urbano-agrícola-industrial (D), as áreas mais favoráveis estão associadas aos terrenos colinosos que acompanham o rio Paraíba do Sul, que estão associados aos sedimentos predominantemente arenosos, ainda que as médias de precipitação sejam relativamente baixas. A região da Bocaina apresenta uma grande área contínua favorável à infiltração, mas que deságua a jusante da represa do Funil, não contribuindo para os dois compartimentos analisados.

Os resultados apontam que os elementos do meio físico naturais e modificados interferem fortemente no processo de infiltração e, na maioria dos casos, necessitam ser avaliados integradamente e não de maneira isolada.

Espera-se que os resultados obtidos neste trabalho possam contribuir como uma ferramenta de gestão e de planejamento territorial visando à preservação dos recursos hídricos na bacia do rio Paraíba do Sul, assim como orientar na implementação de medidas estruturais (como obras de engenharia de drenagem) e medidas não estruturais (como o melhor planejamento do uso da terra no interior da bacia).

\section{AGRADECIMENTOS}

À Fundação de Amparo à Pesquisa do Estado de São Paulo / FAPESP, pelos recursos obtidos através do Programa de Políticas Públicas (Processo 2000/13714-1).

\section{REFERÊNCIAS}

BRAS, R. Hydrology: an introduction to hydrologic science. Reading: Addison-Wesley, 1990. 643p.

BRITO, M. G.; COSTA, C. N.; ALMEIDA, J. A.; VENDAS, D.; VERDIAL, P. H.; Characterization of maximum infiltration using GIS tools. Engineering Geology, Amsterdam, v. 85, p.14-18, 2006. 
CIVITA, M. V.; MAYO, M. Mapping groundwater vulnerability in areas impacted by flash food disasters. In: ESRI EUROPEAN USER CONFERENCE, 13., 1998, Firenze. Proceedings... Disponível em: <http://www.wca-infonet.org/servlet/BinaryDownloader Servlet?filename =1066722282491_wdse12.pdf> . Acesso em: 20 jan. 2008.

COMITÊ DA BACIA DO RIO PARAÍBA DO SUL. CEIVAP Projeto qualidade das águas e controle da poluição hídrica na Bacia do Rio Paraíba do Sul. Relatório Final. São Paulo: Governo de São Paulo / CBH - Rio Paraíba do Sul e Serra da Mantiqueira, 2000. 256p. 1 CD-ROM.

DREW, D. Processos interativos homem-meio ambiente, 3.ed. Rio de Janeiro: Bertrand, 1994. 224p.

DUNNE, T.; LEOPOLD, L. B. Water in environmental planning. San Francisco: W.H. Freeman, 1978. 818p.

FORMAN, R. T. Land mosaics: the ecology of landscape and regions. New York: Cambridge University Press, 1995. 632p.

FORMAN, R. T.; GODRON, M. Landscape ecology. New York: John Willey, 1985. 619p.

GONÇALVES, T. D.; CAMPOS, J. E. G.; BATISTA, G. B.; DINIZ, H. N.; TARGA, M. S. Metodologia para elaboração de mapas hidrogeológicos: estudo de caso da bacia hidrográfica do rio da Palma, DF, Brasil. Revista Ambiente e Água, v. 2, n.2, p. 47-68. 2007.

INSTITUTO TECNOLÓGICO DO ESTADO DE SÃO PAULO (IPT). Mapa geológico do Estado de São Paulo. São Paulo: IPT, 1981. 126p. 1 Mapa, n. 6. Escala 1:500.000.

KWICKLIS, E.; WITKOWSKI, M.; BIRDSELL, K.; NEWMAN, B.; WALTHER, D.; Development of an infiltration map for the Los Alamos area, New Mexico. Madison: Vadoze Zone Journal, v. 4, p. 672-693, 2005.

OLIVEIRA, J. B.; CAMARGO, M. N.; ROSSI, M.; CALDERANO FILHO, B. Mapa Pedológico do Estado de São Paulo. Campinas: Instituto Agronômico de Campinas (IAC), 1999. 1 Mapa. Escala 1:500.000.

PEREIRA, M. N.; NOVO, E. M. L. M.; KURKDJIAN, M. L. N. O.; D’ALGE, J. C. L. Atualização do uso da terra do município de São José dos Campos através de dados de sensoriamento remoto. São José dos Campos: INPE- DPA, 1988. p. 71.

PONÇANO, W. L.; CARNEIRO, C. D. R.; BISTRICHI, C. A.; ALMEIDA, F. F. M.; PRANDINI, F. L. Mapa Geomorfológico do Estado de São Paulo, São Paulo: IPT, 1981. 94p. 1 Mapa. Escala 1:500.000

RAO, V. B.; HADA, K. Characteristics of rainfall over Brazil: annual variation and connections with the Southern oscillation. Berlin: Theoretical \& Applied Climatology, v. 42, p. 81-91, 1990.

REWIS, W. J.; AHUJA, L. R.; BRAKENSIEK, D. L.; SHIRMOHAMMADI, A. Infiltration and soil water movement. In: MAIDMENT D. R. (ed.) Handbook of hydrology. New York: McGraw Hill, 1993. p. 5.1 - 5.51. 
SOARES, P. V.; PEREIRA, S. Y.; SIMÕES, S. J. C.; BERNARDES, G. P.; BARBOSA, S. A. Mapa de infiltração do alto e médio Vale do Paraíba do Sul com base em elementos do meio físico e na precipitação. Ambi-Agua, Taubaté, v. 3, n. 1, p. 26-42, 2008. (doi:10.4136/ambi-agua.40)

ROSS, J. L. S.; MOROZ, I. C. Mapa Geomorfológico do Estado de São Paulo. Revista do Departamento de Geografia, São Paulo, v. 10, p. 41-56, 1997.

SIMÕES, S .J .C.; BARROS, A.P., Regional hydroclimatic variability and Brazil's 2001 energy crisis. Bradford: Management of Environmental Quality, v.18, n.3, p.263273. 2007.

SILVA, J. U. L., A dinâmica atmosférica e a distribuição das chuvas na região nordeste paulista. 1999, 212f. Tese (Doutorado em Geociências) - Instituto de Geociências e Ciências Exatas, Universidade Estadual Paulista, Rio Claro, 1999.

THOMPSON, S. Hydrology for water management. Rotterdam: A. A. Balkema, 1999. 362p.

WARD, A. D.; ELLIOT, W. J. Environmental hydrology. Boca Raton: Lewis Publishers, 1995. 462p. 